\title{
Production of low formaldehyde emission particleboard by using new formulated formaldehyde based resin.
}

\begin{abstract}
In order to preserve the global market competitiveness, the particleboard industry was affronted with challenges to reduce formaldehyde emission while maintaining the quality strength properties of particleboard. To counter the issue, particleboards with five different surface-to-core ratio were fabricated by applying newly formulated UF and MUF resins which were $30 \%$ surface: $70 \%$ core $(3: 7) ; 40 \%$ surface: $60 \%$ core $(4: 6)$; $50 \%$ surface: $50 \%$ core $(5: 5) ; 60 \%$ surface: $40 \%$ core $(6: 4)$ and $70 \%$ surface: $30 \%$ core $(7: 3)$ based on dry particle weight respectively. Formaldehyde emission and strength properties of the fabricated particleboard were investigated based on Japanese Industrial Standard, which are JIS A 1460 and JIS A 5908, respectively. All the MUF-bonded particleboard complied with the type 18 standard, whereas all the UF-bonded particleboard produced complied with type 13 except thickness swelling of the UF-bonded particleboard. The surface-to-core ratio applied in three layered particleboard for both resins exerted considerable influence on the strength properties and formaldehyde emission of particleboards produced from both resins. MUF-bonded particleboard with $40 \%$ surface and $60 \%$ core recorded the lowest formaldehyde emission (0.09 mg L-1) and highest strength properties. For UF-bonded particleboard, the ratio of $60 \%$ surface and $40 \%$ core showed the lowest formaldehyde emission $(0.28 \mathrm{mg} \mathrm{L}-1)$ with better strength properties. This study highlighted the potential of MUF resin to replace UF resin due to its ability to produce $\mathrm{F}^{* * * *}$ particleboard with better strength properties and lower formaldehyde emission according to JIS A 5908.
\end{abstract}

Keyword: Rubberwood particleboard; Japanese industrial standard; Strength properties; Urea formaldehyde; Melamine urea formaldehyde. 